American Journal of Applied Sciences 7 (3): 323-330, 2010

ISSN 1546-9239

(C) 2010Science Publications

\title{
Biomechanical Analysis of Ankle Force: A Case Study for Instep Kicking
}

\author{
${ }^{1}$ A.R. Ismail, ${ }^{2}$ M.R.A. Mansor, ${ }^{2}$ M.F.M. Ali, ${ }^{2}$ S. Jaafar and ${ }^{2}$ N.K. Makhtar \\ ${ }^{1}$ Faculty of Mechanical Engineering, University Malaysia Pahang, \\ 26600 Pekan, Pahang, Malaysia \\ ${ }^{2}$ Department of Mechanical and Materials Engineering, \\ Faculty of Engineering and Built Environment, \\ University Kebangsaan Malaysia, 43600 UKM Bangi, Malaysia
}

\begin{abstract}
Problem statement: The objective of this study was to identify, analyze and build the force equation that involved the velocity, acceleration, angle and distance at the ankle when making the instep kick. Approach: One subject which is a male national soccer player had been chosen as a subject for the study. The subject was selected from professional soccer player with average heights of Asian. Subject has to make first step run instep kick which used internal body energy. Subject needs to repeat this method for 5 times to get the average data. The variable examined was the velocity, acceleration, distance and the angle of the ankle that significant or not significant to the force model when instep kick being made. Biomechanical analysis will be done be the application of Silicon Pro Coach and Statistical Package for The Social Sciences (SPSS) for the statistical analysis. The video of instep kicking will be capture during the study to get a real visual of kicking to be analyzed. From that, the data for velocity, acceleration, angle of ankle and distance when kicking being made can be verified. All the data was measured using by Silicon Pro Coach which is capable to measure the velocity, acceleration, distance and the angle of the ankle. Further, the equation that related with the variables will identify according the result from SPSS which is from table of summary for regression model, ANOVA of regression model and coefficient of regression model for each variable. From there, the variables will be recognized significant or insignificant to the force model and the force equation model will be determined. Results: The Highest average force and average velocity for this study is $9866.4 \mathrm{~N}$ and $15.952 \mathrm{~m} \mathrm{sec}^{-1}$. Other than that, the objective to come out with one force equation which cover all the parameters involved has been done using SPSS software which includes some assumptions. Conclusion: The study revealed that the dominant variables contribute to the force rate is the velocity and the distance. From this study, it will help our soccer team to build and define the best solution to improve their performance.
\end{abstract}

Key words: Biomechanics, acceleration, velocity, distance, angle

\section{INTRODUCTION}

The word biomechanics can be divided into two parts: the prefix bio-and the root word mechanics. The prefix bio-indicates that biomechanics has something to do with living or biological systems. The root word mechanics indicates that biomechanics has something to do with the analysis of forces and their effects. Biomechanics is the study of the structure and function of biological systems by means of the methods of mechanics. Biomechanics is the study of the structure and function of biological systems by means of the methods of mechanics (Hatze, 1974). Biomechanics includes the study of all living things, plant and animal; animal bio mechanics includes only animals as subjects of study; human biomechanics includes only human; and exercise and sport biomechanics includes only humans involved in exercise and sport (McGinnis, 1999). We might define exercise and sport biomechanics as the study of forces and their effects on humans in exercise and sport.

Nowadays, human daily activities are influenced by the growth of science and technology. This growth been used by researchers to rebuild and develop various field in this world including sports and recreation.

In the urbanized countries, many research studies had been done on this field and been commercialized

Corresponding Author: A.R. Ismail, Faculty of Mechanical Engineering, University Malaysia Pahang, 26600 UMP Pekan, Pahang, Malaysia 
which covered the performance of the athlete in all kind of sports using the biomechanics' approach. Modern foot ball need high physical state level during competition season. As such, either from preparation important goal training programmed was to improve specific strength football. Specific strength football was the concept often used in training and can be defined as footballer capacity to use muscle strength effectively and consistent during season game and total. During game take place, every player display several dynamic movements such as heading, speed, tackling, and kicking which required strength level, muscle energy and resilience steady (Manopoulos et al., 2004). Instep kicking has been studied from the youngest age groups to seasoned professionals (Kellis et al., 2004; Dorge et al., 2002). Here, reduced ball velocities for the inner and outer instep kicking techniques are traded to ball spin achieved by off-centered foot/ball contact.

The maximum speed of ball kicked and angular velocity is advancing by age increase (Luhtanen, 1988). The ball velocity advancing by age probably caused muscle mass expansion and also increase in kicking technique. The instep kick been chosen for analysis at this time because no research made on this skill among elite players and also because of kick skill interest in football. The dominant limb instead of dominant examined because bilateral capacity development is particularly important in skill in football such as instep kick (Barfield et al., 2002).

However in Malaysia, this kind of research is one of the new approaches in identifying the sports development and at the same time improvises it. As we all know, Malaysia's achievement in soccer sport is quite low. Therefore, this study is focusing more on the biomechanics analysis towards the soccer players besides to identify and investigate the problems of their kick. In this research, the quantitative biomechanics analysis is applied. If something implementation aspect in survey or calculated results of the analysis based on that the measurement was biomechanics analysis quantitative. On the other hand, if the aspect is assessed by observation, this result of the analysis is known as qualitative analysis (McGinnis, 1999). Biomechanics might provide with some insights to answers this and other questions about human movement.

\section{MATERIALS AND METHODS}

Subject selection: Height, weight, age and body size of the subject was considered as data for analysis. Most important thing is subject has to be in good health during experiment because the kick that will be done is from self force. The subject was selected from professional soccer player of Malaysia with average heights of Asian. Observation started when subject stops kicking the ball where posture of the leg from waist to knee and then to ankle was observed. The instep kick was selected for analysis because, at this time, there are no studies of this principle skill among elite female soccer players, and the importance of this particular skill in the game of soccer. Dominant and no dominant limbs were examined because of the importance of developing similar bilateral ability, especially in a skill as crucial to success in soccer as instep kicking (Barfield et al., 2002).

Experimental setup: On the lower limb of the subject which from waist to ankle, deflection marker will be used for data recording for analysis. Data recording will be done with video/picture using Sony video camera. This camera can analyze as much as $0.02 \mathrm{sec}$ per frame. Preparation for data recording is show in Fig. 1.

Data analysis: From taken video, kicking analysis can be made with the use of Sillicon Pro Coach software. Velocity, acceleration and angle at ankle need to be analyzing for each frame. This data will be used for calculation to search for force while kicking.

Statistical analysis: Statistical analysis will be done using Statistical Package for The Social Sciences (SPSS) software. The results determine the correlation between each parameter towards the force model that will be made.

Kicking suggestion: The dominant factors for acceleration of velocity and force that has been made during kicking need to be identified in order to see whether the factor give effects to ball kicking. Following this, suggestion of the way of kicking can be proposed according to the factors that have been identified. Below is the flow chart for the method used in this experiment (Fig. 2).

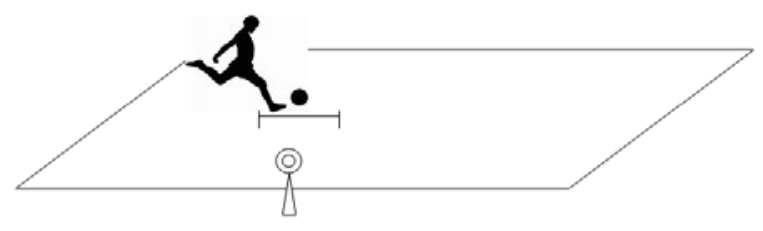

Fig. 1: Experimental design 
Am. J. Applied Sci., 7 (3): 323-330, 2010

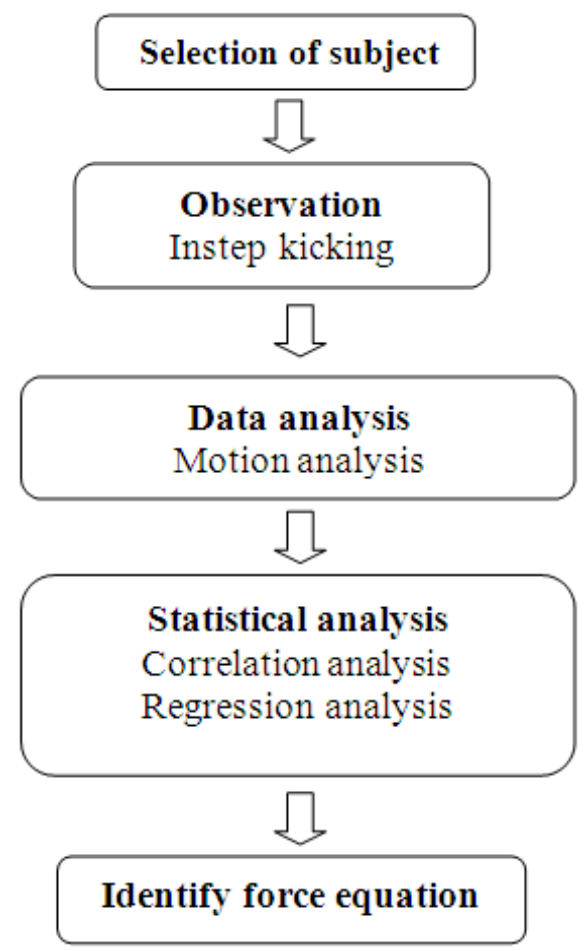

Fig. 2: Flow chart of the experiment

\section{RESULTS}

Kicking pictures: Kicking observation was conducted by video recording and edited by making pictures according to frame which is for every 0.02 sec before kicking until after kicking was done. Figure 3 show the editing pictures according to frame and it show the subject body position and movement during kicking. The kicking observation was recorder when the subject started kicking the ball until finished kicking the ball. Kicking in each frame will be analyzed according to angle, acceleration, kicking velocity and frame distance at ankle.

Kicking data: Figure 4 shows the distance made during kicking for each frame. This distance includes ankle movement of the subject. This mean, for every 0.02 seconds, the distance for both segments is different and cumulative distance will be given in the issued table. The instep kick was done for 5 times.

Figure 5 shows the angle during kicking including before and after kicking has been made. The angle value was also obtained at each frame. This angle was measured from hip point, knee point and ankle point on the kicking leg.

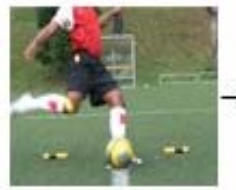

Framel

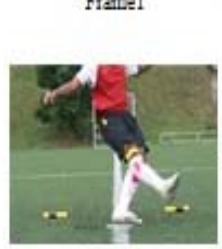

Frame 6

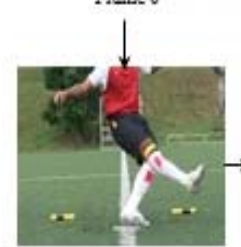

Frame?

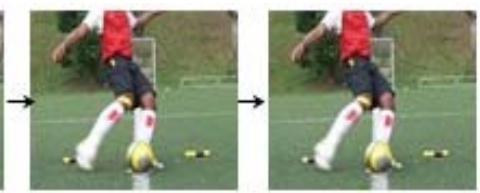

Frame 2

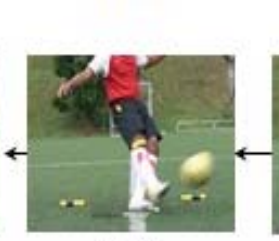

Frame 5

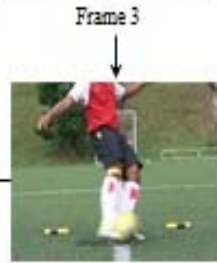

Frame 4

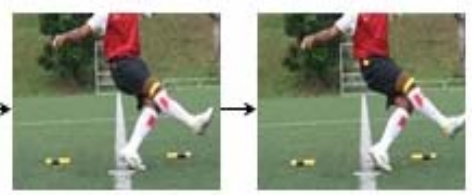

Frame 8

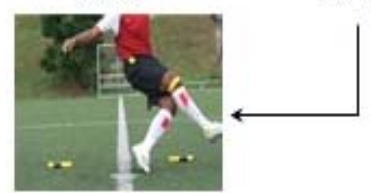

Frame 10

Fig. 3: Kicking pictures according to frame

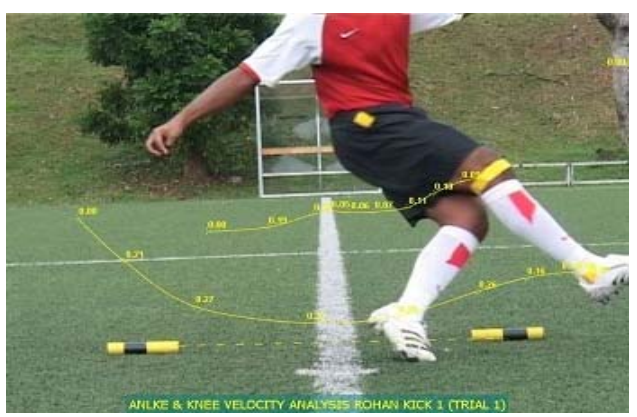

Fig. 4: Kicking distance

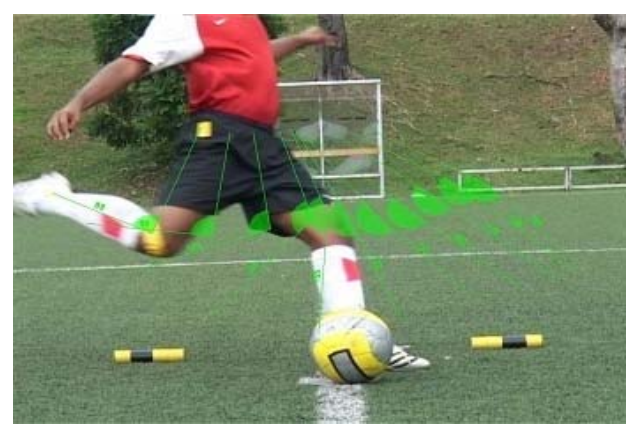

Fig. 5: Kicking angle 
Am. J. Applied Sci., 7 (3): 323-330, 2010

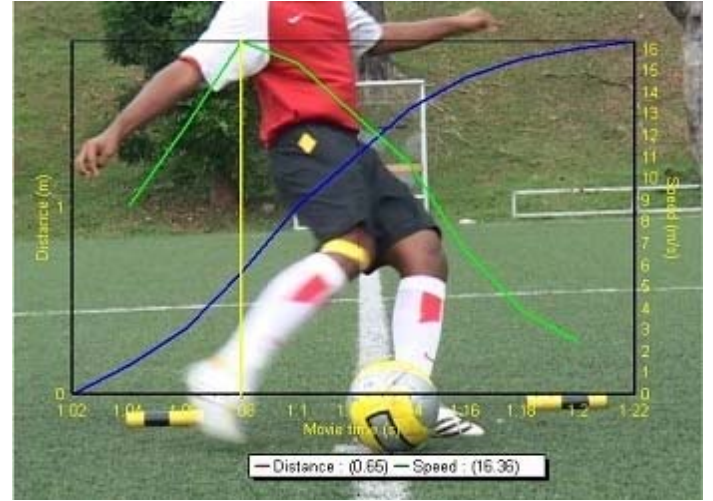

Fig. 6: The velocity versus time at ankle

The Fig. 6 shows the analysis results of relationship between velocity, time in each frame and kicking distance. It shows, the maximum velocity was achieved before the leg hit the ball. The ball speed of the soccer kick depends on the speed of the foot before impact and the mechanics of the collision between the foot and the ball. The coefficient of restitution assesses how the collision is modified by material properties of the colliding objects (Lees, 1996). From Fig. 6 it also show that the time velocity and distance are the dependent variable while kicking. The ball speed depends on the velocity of the foot (distal segment) upon impact as well as the quality of ball-foot impact (Bull-Andersen et al., 1999; Nunome et al., 2002; Levanon and Dapena, 1998). The correlation coefficients between ball and foot speed reported in the literature are high $(r>0.74)$ (Asami and Nolte, 1983; Nunome et al., 2006; Levanon and Dapena, 1998). The higher the speed of the foot before impact, the shorter the foot-ball contact and the highest the ball speed. For this reason, the ball-to-foot speed ratio has been considered as an index of a successful kick (Kellis et al., 2004; Asami and Nolte, 1983; Nunome et al., 2006). For the instep kicks, ball-to-foot speed ratios reported in the literature range from 1.06 to 1.65 (Kellis et al., 2004; Asami and Nolte, 1983; Nunome et al., 2006). Depending on the foot area used to examine foot speed. The mechanism of collision between the foot and the ball could be described by the following equation (Lees and Davies, 1988):

$\mathrm{V}_{\text {ball }}=\mathrm{V}_{\text {foot }} \cdot \mathrm{M} \cdot(\mathrm{i}+\mathrm{l}) /(\mathrm{M}+\mathrm{m})$

Where:

$\mathrm{V}_{\text {ball }}=$ Velocity of the ball

$\mathrm{V}_{\text {foot }}=$ Velocity of the foot

$\mathrm{M} \quad=$ Effective striking mass of the leg $\mathrm{m} \quad=$ Mass of the ball

$1=$ The coefficient of restitution

The term $(1+\mathrm{l})$ is related to the firmness of the foot at impact and the ratio $\mathrm{M} /(\mathrm{M}+\mathrm{m})$ provides an indication of the rigidity of the foot and leg at impact. A different equation to describe the velocity of the ball after foot impact was developed by Bull-Andersen et al., (1999):

$\mathrm{V}_{\text {ball }}=\mathrm{I}_{\mathrm{f}} \mathrm{V}_{\mathrm{f} \text { before }}(1+\mathrm{l}) / \mathrm{I}+\mathrm{m}_{\text {ball }} \mathrm{r}^{2}$

Where:

$\mathrm{V}_{\text {ball }}=$ Velocity of the ball

I = The moment of inertia of the shank-foot segment about the knee joint

$\mathrm{V}_{\mathrm{f}, \text { before }}=$ Velocity of the foot before impact

$l=$ The coefficient of restitution

$\mathrm{m}_{\text {ball }}=$ The mass of the ball

$\mathrm{r}^{2} \quad=$ The distance between the knee joint and the centre of the ball as well as the distance between the knee joint and the point of contact on the foot (the length $r$ is the same between these points)

The coefficient of restitution was defined as:

l. $\left(\mathrm{V}_{\mathrm{f}, \text { before }}-\mathrm{V}_{\text {ball,before }}\right)=-\left(\mathrm{V}_{\mathrm{f}, \text { after }}-\mathrm{V}_{\text {ball }}\right)$

Where:

$\mathrm{V}_{\mathrm{f} \text {,before }}=$ The velocity of the foot before impact

$\mathrm{V}_{\mathrm{f} \text {,after }}=$ The velocity of the foot after impact

$\mathrm{V}_{\text {ball }}=$ The velocity of the ball

The coefficient of restitution quantifies the extent to which a perfect collision is modified by the material properties of the colliding objects. A perfect elastic collision demonstrates an $\mathrm{l}=1$ (Bull-Andersen et al., 1999). The coefficient of restitution ranges from 0.4630.681 (Bull-Andersen et al., 1999; Dorge et al., 2002). It has been suggested that a change in the coefficient of restitution from $0.5-0.65$ would lead to a $10 \%$ rise in ball speed (Bull-Andersen et al., 1999). The coefficient depends on the mechanical properties of the ball, the shoe, the ankle and the foot upon impact (BullAndersen et al., 1999; Asami and Nolte, 1983). Upon ball contact the foot moves simultaneously with the ball for a distance equal to approximately the $2 / 3$ of the diameter of the ball (Nunome et al., 2002). Moreover, large deformation appears during ball impact which causes increased forces (Nunome et al., 2002) and releases energy (Tsaousidis and Zatsiorsky, 1996). Consequently, apart from the phenomena observed 
during the pre-impact phase, it is necessary to understand the importance and the mechanisms during the collision phase.

Particularly, the coefficient of restitution would depend on the amount of deformation of the foot and the ball at impact. The less deformation by the foot, the higher the coefficient of restitution. The amount of deformation depends on the effective striking mass which is the equivalent of the striking object (in this case, the foot and shank). The effective striking mass increases as the limb becomes more rigid by muscle activation (Lees and Davies, 1988). This takes place when the contact point is located closer to the ankle rather than the metatarsals (Asami and Nolte, 1983). Based on Eq. 2, ball velocity can also be affected by the moment of inertia of the shank-foot segment. BullAndersen et al. (1999) showed that alterations in moment of inertia did not affect the velocity of the ball. It appears, therefore, that rotating the whole leg at the time of impact would lead to lower velocity of the foot and the ball. If the aim of the kick is to maximize ball velocity, then this technique is not recommended BullAndersen et al. (1999).

The above studies suggest that execution of a kick which aims to maximize ball velocity largely depends on the high velocity of the foot prior to impact and a small foot deformation at impact. Using a different methodological approach, Tsaousidis and Zatsiorsky (1996) estimated that more than $50 \%$ of the ball's speed is imparted to the ball without any contribution of the potential energy of the ball deformation. It was suggested that ball speed is affected by two factors Tsaousidis and Zatsiorsky (1996). First, the energy or momentum which is a result of the co-ordinate movement and mechanical behavior of the foot before impact and second, energy which is due to muscle work produced the collision phase (Kellis and Katis, 2007).

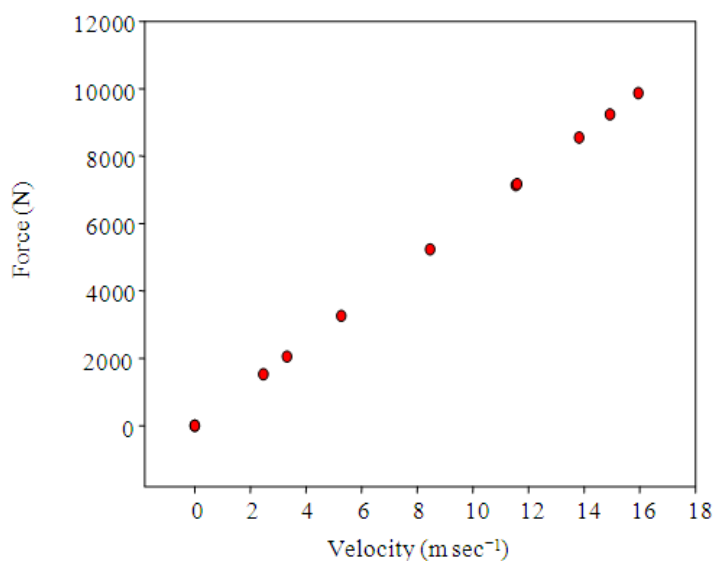

Fig. 7: Graph of force versus velocity
Statistic analysis for ankle force: The data above will transfer into Statistical Package for the Social Sciences (SPSS) to analyze and find the correlation for each variable to the force when produce from kicking.

Graph: The graphs in Fig. 7-9 show the force versus each variable to show the linear of the graph. The graphs in Fig. 7-9 taken out from SPSS software.

Figure 7 and 8 shows that the force linearly with velocity and distance while kicking, where, when the value of velocity is increased, the force produced also increased. Based on Fig. 8 show that the data is not uniform but it tend to linear to the force. So, this will give the group of score will more uniform at regression line. This means those variables above are accepted as significant. From Fig. 9, the graph plotted not uniform and not linearly. This showed that the variable not accepted and not significant.

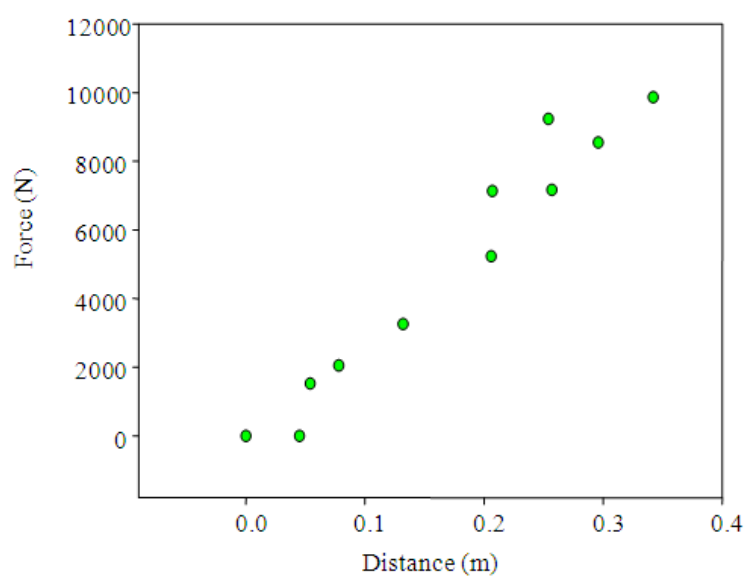

Fig. 8: Graph of force versus distance

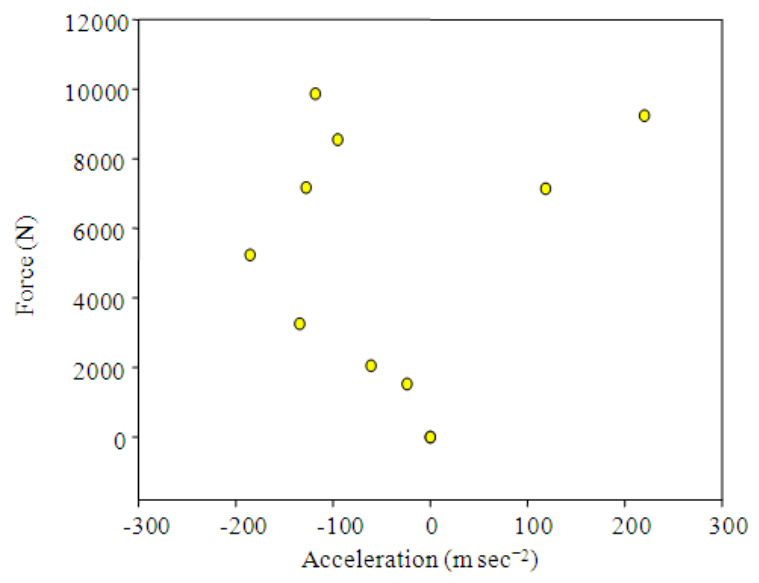

Fig. 9: Graph of force versus acceleration 
Am. J. Applied Sci., 7 (3): 323-330, 2010

Table 1: Correlation kicking parameter to force model

\begin{tabular}{lll}
\hline Kicking parameter & Correlation & Value \\
\hline Velocity variable & Pearson correlation & $1.000^{* *}$ \\
with force model & significant (2-tailed) & 0.000 \\
Acceleration variable & Pearson correlation & 0.093 \\
with force model & significant (2-tailed) & 0.785 \\
Distance while kicking & Pearson correlation & $0.976^{* *}$ \\
variable with force model & significant (2-tailed) & 0.000 \\
\hline
\end{tabular}

**: Correlation significant at the 0.01 level (2- tailed)

Table 2: Summary of regression for velocity variable

\begin{tabular}{lllll}
\hline Model & $\mathrm{R}$ & $\mathrm{R}^{2}$ & $\begin{array}{l}\text { Adjusted } \\
\mathrm{R}^{2}\end{array}$ & $\begin{array}{l}\text { Std. error of } \\
\text { the estimate }\end{array}$ \\
\hline 1 & $1.000(\mathrm{a})$ & 1.000 & 1.000 & 0.179222 \\
\hline
\end{tabular}

Table 3: Summary of regression model for acceleration variable

\begin{tabular}{lllll}
\hline Model & $\mathrm{R}$ & $\mathrm{R}^{2}$ & $\begin{array}{l}\text { Adjusted } \\
\mathrm{R}^{2}\end{array}$ & $\begin{array}{l}\text { Std. error of } \\
\text { the estimate }\end{array}$ \\
\hline 1 & $0.093(\mathrm{a})$ & 0.009 & -0.101 & 3887.882950 \\
\hline
\end{tabular}

Correlation analysis: Table 1 show the correlation analysis to determine the relationship between force model with every variable which is the velocity, acceleration and distance while kicking. The objective for this analysis is to identify the variable which is most dominant to force model. Based on Table 1, Pearson correlation show that the velocity and distance while kicking is the significant variable at the 0.01 level (2tailed). According to the correlation value above showed that the velocity and distance while kicking have the high range. It is mean that both of this variable have the high significant to the force model.

\section{Regression analysis:}

Velocity variable: Table 2 shows the summary of regression for velocity variable. The productivity regression model, $\mathrm{R}^{2}=1.000$ and the output reports $\mathrm{R}^{2}$ $\times 100 \%=100$.

For this result the output, $\mathrm{d}$, a, and $\mathrm{v}$ are denoted as distance, acceleration and velocity. The SPSS output show that the least square point estimates of the model parameter are $b_{0}=0.026, b_{1}=0, b_{2}=0$ and $b_{3}=$ 618.506 where $b_{1}$ is distance, $b_{2}$ is acceleration and $b_{3}$ is the Velocity. The least square prediction equation is:

$$
F=0.026+618.506 \mathrm{v}
$$

Acceleration variable: Table 3 shows a of regression model for acceleration variable. The productivity regression model, $\mathrm{R}^{2}$ as the coefficient of the multiple determinations for the productivity regression model, $\mathrm{R}^{2}=0.009$ and the output reports $\mathrm{R}^{2} \times 100 \%=0.9 \%$. This can be interpreted as indicating that the model containing acceleration for approximately $0.9 \%$ of the observed variability in force.
Table 4: Summary of regression model for distance variable while kicking

\begin{tabular}{lllll}
\hline Model & $\mathrm{R}$ & $\mathrm{R}^{2}$ & $\begin{array}{l}\text { Adjusted } \\
\mathrm{R}^{2}\end{array}$ & $\begin{array}{l}\text { Std. error of } \\
\text { the estimate }\end{array}$ \\
\hline 1 & $0.976(\mathrm{a})$ & 0.952 & 0.947 & 855.245085 \\
\hline
\end{tabular}

Table 5: Summary of regression model for all variables

\begin{tabular}{lllll}
\hline Model & $\mathrm{R}$ & $\mathrm{R}^{2}$ & $\begin{array}{l}\text { Adjusted } \\
\mathrm{R}^{2}\end{array}$ & $\begin{array}{l}\text { Std. error } \\
\text { of estimate }\end{array}$ \\
\hline 1 & $1.000(\mathrm{a})$ & 1.000 & 1.000 & 0.179222 \\
\hline
\end{tabular}

For this result the output, $\mathrm{d}$, a, and $\mathrm{v}$ are denoted as distance, acceleration and velocity. The SPSS output show that the least square point estimates of the model parameter $b_{0}=5017.751, b_{1}=0, b_{2}=2.887$ and $b_{3}=0$ where $b_{1}$ is distance, $b_{2}$ is acceleration and $b_{3}$ is the velocity. The least square prediction equation is:

$$
\mathrm{F}=5017.751+2.887 \mathrm{a}
$$

Distance variable while kicking: Table 4 shows the summary of regression model for distance variable while kicking. It show that the productivity regression model, $\mathrm{R}^{2}=0.952$ and the output reports $\mathrm{R}^{2} \times 100 \%=$ $95.2 \%$. This can be interpreted as indicating that the model containing distance for approximately $95.2 \%$ of the observed variability in force.

The SPSS output summarize that the least square point estimates of the model parameter are $b_{0}=$ 467.914, $b_{1}=31624.529, b_{2}=0$ and $b_{3}=0$ where $b_{1}$ is distance, $b_{2}$ is acceleration and $b_{3}$ is the velocity. The least square prediction equation is:

$$
F=-467.914+31624.52 d
$$

All Variable: Table 5 shows the summary of regression model for all variable. It show that the productivity regression model, $\mathrm{R}^{2}=1.000$ and the output reports $\mathrm{R}^{2}$ $\times 100 \%=100 \%$. This can be interpreted as indicating that the model containing distance, acceleration and speed for approximately $100 \%$ of the observed variability in force.

For this result it show that the least square point estimates of the model parameter are $b_{0}=0.50, b_{1}=$ $1.201, b_{2}=0$ and $b_{3}=618.528$ where $b_{1}$ is distance, $b_{2}$ is acceleration and $b_{3}$ is the velocity. The least square prediction equation is:

$$
F=0.50-1.201 d+618.528 v
$$

\section{DISCUSSION}

After go through for each data that provided through analysis, there have the significant and no 
significant variable for ankle. For the ankle analysis there are 2 variable that significant to the force model which are velocity and distance while kicking but when we do the absolute for the acceleration data, given that the acceleration has significant to the model. It can be proving from the correlation that gives by SPSS.

Ankle sprain are arguably the most common sports injury. The ankle sprain is the most common injury in soccer Ekstrand and Gillquist, (1983). When the foot is plantar flexed at touchdown, it may also increase the ground reaction force moment arm about the subtalar joint (Barrett and Bilisko, 1995).

Ball impact was predominantly made with the anteromedical aspect of the foot and ankle, with impact between the ball and the base of the first metatarsal bone in $89 \%$ of the kicking action and between the ball and the anterior part of the medical malleolus in $76 \%$. The data on impact location and impact force support the hypothesis that spur formation in anterior ankle impingement syndrome is related to recurrent ball impact, which can be regarded as repetitive microtrauma to the anteromedical aspect of ankle. The increased traction increases foot fixation. This foot fixation increases the vulnerability of all of the lower joints of the leg, in particular, the ankle.

This can prove also that the higher the speed of the foot before impact, the shorter the foot-ball contact and the highest the ball speed. For this reason, the ball-tofoot speed ratio has been considered as an index of a successful kick (Kellis et al., 2004; Nunome et al., 2006).

\section{CONCLUSION}

The highest average force is $9866.4 \mathrm{~N}$ at $15.952 \mathrm{~m}$ $\mathrm{sec}^{-1}$ average velocity. Other than that, the objective to come out with one force equation which cover all the parameters involved has been done using SPSS software which includes some assumption. The force equations for ankle are as follow:

$$
F=0.50-1.201 d+618.528 v
$$

\section{REFERENCES}

Asami, T. and V. Nolte, 1983. Analysis of Powerful ball kicking. In: Biomechanics VIII-B, Matsui, H. and K. Kobayashi (Eds.). Human Kinetics, Champaign IL., pp: 695-700.

Barfield, W.R., D.T. Kirkendall and B. Yu, 2002. Kinematic instep kicking differences between elite female and male soccer players. J. Sports Sci. Med. 3: 72-79.
Barrett, J. and T. Bilisko, 1995. The role of shoes in the prevention of ankle sprains. Sports Med., 20: 277280. http://www.biomech.com/full_article/?ArticleID=4 57\&month $=07 \&$ year $=2006$

Bull Andersen, T., Dorge and Thomsen, 1999. Collisions insoccer kicking. Sports Eng., 2: 121125. DOI: 10.1046/j.1460-2687.1999.00015

Dorge, H.C., T. Bull-Andersen, H. Sorensen and E.B. Simonsen, 2002. Biomechanical differences in soccer kicking with the preferred and the nonpreferred leg. J. Sports Sci., 20: 293-299. DOI: 10.1080/026404102753576062

Ekstrand, J. and J. Gillquist, 1983. The avoidability of soccer injuries. Int. J. Sport Med., 4: 124-128. http://www.physioroom.com/research/stretching_1. php

Hatze, H., 1974. The meaning of term biomechanics. J. Biomech., $\quad 7$ : 189-190. http://www.pubmedcentral.nih.gov/articlerender.fc gi?artid $=1888377$

Kellis, E., A. Katis and I. Gissis, 2004. Knee biomechanics of the support leg in soccer kicks from three angles of approach. J. Med. Sci. Sports Exerc., 36: 1017-1028. PMID: 15179172

Kellis, E. and A. Katis, 2007. Biomechanical characteristics and determinants of instep soccer kick. J. Sports Sci. Med., 6: 154-165. http://www.jssm.org/vol6/n2/1/v6n2-1pdf.pdf

Lees, A. and T. Davies, 1988. The effects of fatigue on soccer kick biomechanics (abstract). J. Sports Sci., 8: 156-157.

Lees, A., 1996. Biomechanics Applied to Soccer Skills. In: Science and Soccer, Reilly, T. (Ed.). E \& FN Spon, London, ISBN 0-203-41755-0, pp: 123-133.

Levanon, J. and J. Dapena, 1998. Comparison of the kinematics of the full-instep and pass kicks in soccer. Med. Sci. Sports Exerc., 30: 917-927. http://www.thefreelibrary.com/Biomechanical+cha racteristics+and+determinants + of + instep + soccer $+k$ ick.-a0168872795

Luhtanen, P., 1988. Kinematics and kinetics of Maximal Instep Kicking in Junior Soccer Players. In: Science and Football, Reily, T., A. Lees, K. Davids and W.J. Murphy (Eds.). E \& FN Spon, London, ISBN: 0-203-41755-0, pp: 441-448.

Manopoulos, E., C. Papadopoulus and E. Kellis, 2004. Effect of combined strength and kick coordination training on soccer kick biomechanics in armature players. Scand J. Med. Sci. Sport, 16: 102-110. http://www.thefreelibrary.com/Biomechanical+cha racteristics+and+determinants + of + instep + soccer $+\mathrm{k}$ ick.-a0168872795 
McGinnis, P.M., 1999. Biomechanics of Sport and Exercise Human Kinetics. Champaign, Illinois, ISBN: 9780736051019 , pp: 406.

Nunome, H., T. Asai, Y. Ikegami and S. Sakurai, 2002. Three dimensional kinetic analysis of side-foot and instep soccer kicks. Med. Sci. Sports Exerc., 34: 2028-2036. PMID: 12471312

Nunome, H., M. Lake, A. Georgakis and L.K. Stergioulas, 2006. Impact phase kinematics of instep kicking in soccer. J. Sports Sci., 24: 11-22. http://www.thefreelibrary.com/Biomechanical+cha racteristics+and+determinants + of + instep + soccer $+k$ ick.-a0168872795
Tsaousidis, N. and V. Zatsiorsky, 1996. Two types of ball-effector interaction and their relative contribution to soccer kicking. Hum. Move. Sci., 15: 861-876. DOI: 10.1016/S0167-9457(96)00027-9 